\title{
ASPECTOS RELACIONADOS COM A EMISSÃO DE METANO DE ORIGEM RUMINAL EM SISTEMAS DE PRODUÇÃO DE BOVINOS
}

\section{(Ruminal methane emission related aspects in cattle production systems)}

\author{
PEDREIRA, M.S.'; OLIVEIRA, S.G.'; BERCHIELLI, T.T. ${ }^{3}$; PRIMAVESI, O. ${ }^{4}$ \\ 'Departamento de Tecnologia Rural e Animal da Universidade Estadual do Sudoeste da Bahia, Itapetinga, \\ BA, Brasil; \\ ${ }^{2}$ Programa de Pós-graduação em Zootecnia, FCAV/UNESP - Jaboticabal, SP, Brasil; \\ ${ }^{3}$ Departamento de Zootecnia - FCAV/Unesp, Pesquisadora do CNPq - Departamento de Zootecnia - Via de \\ Acesso Prof. Paulo Donato Castellane, s/n - Jaboticabal, SP, Brasil - CEP 14884-900, \\ ttberchi@fcav.unesp.br - Autor para correspondência; \\ ${ }^{4}$ Embrapa/CPPSE - São Carlos, SP, Pesquisador do CNPq.
}

\begin{abstract}
RESUMO - O gás metano possui reconhecidamente um importante papel como intensificador do efeito estufa. Pelo seu processo digestivo de fermentação entérica, os ruminantes convertem os carboidratos presentes na dieta em ácidos graxos voláteis, resultando na produção de dióxido de carbono e metano. Dessa forma, os ruminantes são reconhecidos como importantes emissores de metano ruminal para a atmosfera, sendo que a produção deste gás representa ainda perdas energéticas para os animais em relação à energia consumida. Animais consumindo dietas de baixa qualidade podem produzir mais metano por unidade de produto (carne ou leite) em relação aos animais de alta produção consumindo dietas de melhor qualidade em maiores níveis de ingestão. Resultados têm mostrado que a redução da emissão de metano pela pecuária está ligada à melhoria da dieta, à melhoria dos pastos, à suplementação alimentar, à seleção por maior potencial genético de produção e a outras medidas que reflitam na melhor eficiência produtiva, resultando em menores ciclos de produção.
\end{abstract}

Palavras-chave: Fermentação ruminal, metano, produção animal, efeito estufa, ruminantes.

ABSTRACT - Methane is well known as a greenhouse
effect intensifier. Ruminants, during the ruminal digestive
fermentation process, transform carbohydrates available
in the diet to volatile fatty acids, with production of carbon
dioxide and methane. Therefore, ruminants are known
as important methane source to the atmosphere.
Methane production also means animal losses of
ingested energy. Ruminal fermentation process is driven
by dry matter intake, and feed quality. Therefore,
consume of low quality diets will produce more methane
per product unit (milk or beef) compared to high
producing animals ingesting great amounts of high quality
diets. The sulphur hex fluoride gas tracer technique did
allow good methane emission measurements by grazing or free managed animals. Results show that the reduction of methane emission by cattle is related to better quality diet, to improvement of forage quality of pastures, to grain inclusion in diet, to animal breeds with greater production potential, and other practices that improve production efficiency, and result in shorter production cycles.

Key-words: Animal production, greenhouse effect, methane, ruminal fermentation, ruminants.

\section{Introdução}

A interação entre os fatores de produção animal e o impacto ambiental causado pelas diversas atividades tem sido, cada vez mais, o objetivo de pesquisas relacionadas com as mudanças climáticas mundiais. Os ruminantes, devido ao processo digestivo de fermentação entérica, são reconhecidos como importante fonte de emissão de metano $\left(\mathrm{CH}_{4}\right)$ para a atmosfera. Além disso, a produção desse gás, que pode variar em função do sistema de alimentação, é considerada uma parte perdida da energia do alimento, refletindo em ineficiência na produção animal.

Baseado em aspectos de proteção mercadológica, o Brasil, por ser detentor do maior rebanho comercial de bovinos do mundo e por utilizar forrageiras tropicais como base da alimentação destes animais, tem sido indicado como importante produtor de $\mathrm{CH}_{4}$, fato que pode ser utilizado como embargo aos produtos da pecuária destinados à exportação.

Atualmente, as pressões ambientais indicam ser a redução da emissão de $\mathrm{CH}_{4}$ de origem pecuária, um dos principais fatores para nortear as pesquisas com a produção de ruminantes (MACHMÜLLER, 2006). Sendo assim, objetivou-se, nesta revisão, abordar os aspectos quantitativos da produção de $\mathrm{CH}_{4}$ ruminal, bem como avaliar os aspectos relacionados com a alimentação envolvidos na sua produção. 
Aspectos relacionados com a emissão de metano de origem ruminal em sistemas de produção de bovinos

\section{Aspectos quantitativos da produção de metano}

As maiores fontes de emissão de $\mathrm{CH}_{4}$ considerando as atividades agrícolas são representadas pela fermentação entérica em ruminantes, produção de arroz em terrenos alagados e fermentação de dejetos da pecuária (OLESEN et al., 2006). De acordo com HARPER et al. (1999), a produção de arroz em terrenos alagados contribui com $11 \%$ do total de $\mathrm{CH}_{4}$ liberado para a atmosfera, a fermentação entérica em animais com $16 \%$ e a fermentação de dejetos com $17 \%$.

$\mathrm{O} \mathrm{CH}_{4}$, além de ser caracterizado como um importante gás de efeito estufa, contribuindo com cerca de $15 \%$ para o aquecimento global (TABELA 1), tem relação direta com a eficiência da fermentação ruminal em virtude da perda de carbono e, conseqüentemente, perda de energia, determinando maior ou menor desempenho animal (COTTON e PIELKE, 1995).

TABELA 1 - GASES ATMOSFÉRICOS, FONTES E CONTRIBUIÇÃO PARA O AUMENTO DO EFEITO ESTUFA.

\begin{tabular}{|c|c|c|c|c|c|}
\hline & $\begin{array}{c}\text { Gás Carbônico } \\
\left(\mathrm{CO}_{2}\right)\end{array}$ & $\begin{array}{l}\text { Metano } \\
\left(\mathrm{CH}_{4}\right)\end{array}$ & $\begin{array}{l}\text { Óxido Nitroso } \\
\qquad\left(\mathrm{N}_{2} \mathrm{O}\right)\end{array}$ & $\begin{array}{l}\text { Clorofluor- } \\
\text { carbonetos } \\
\text { (CFCs) }\end{array}$ & Ozônio $\left(\mathrm{O}_{3}\right)$ \\
\hline $\begin{array}{l}\text { Principal } \\
\text { fonte } \\
\text { antrópica }\end{array}$ & $\begin{array}{l}\text { Combustíveis } \\
\text { fósseis, } \\
\text { desmatamento }\end{array}$ & $\begin{array}{l}\text { Arroz cultivo } \\
\text { inundado, } \\
\text { pecuária, } \\
\text { combustíveis } \\
\text { fósseis, } \\
\text { queimadas }\end{array}$ & $\begin{array}{l}\text { Fertilizantes } \\
\text { conversão do } \\
\text { uso da terra }\end{array}$ & $\begin{array}{c}\text { Refrigeradores, } \\
\text { aerossóis, } \\
\text { processos } \\
\text { Industriais }\end{array}$ & $\begin{array}{l}\text { Hidrocarbonetos } \\
\text { (com NOx), } \\
\text { queima de } \\
\text { biomassa }\end{array}$ \\
\hline $\begin{array}{l}\text { Tempo de } \\
\text { vida na } \\
\text { atmosfera }\end{array}$ & $50-200$ anos & 10 anos & 150 anos & $60-100$ anos & $\begin{array}{l}\text { Semanas a } \\
\text { meses }\end{array}$ \\
\hline $\begin{array}{l}\text { Taxa anual } \\
\text { de aumento }\end{array}$ & $0,5 \%$ & $0,9 \%$ & $0,3 \%$ & $4 \%$ & $0,5-2,0 \%$ \\
\hline $\begin{array}{l}\text { Contribuição } \\
\text { relativa ao } \\
\text { efeito estufa }\end{array}$ & $60 \%$ & $15 \%$ & $5 \%$ & $12 \%$ & $8 \%$ \\
\hline
\end{tabular}

Adaptado de MCT (2000).

As emissões globais geradas a partir dos processos entéricos são estimadas em 80 milhões de toneladas por ano (USEPA, 2000), correspondendo a cerca de $22 \%$ das emissões totais de $\mathrm{CH}_{4}$ geradas por fontes antrópicas (FIGURA 1), representando $3,3 \%$ do total dos gases de efeito estufa, o que significa importante papel nas modificações climática no mundo, exemplificada especialmente pelo contínuo aumento do aquecimento global.

FIGURA 1 - FONTES ANTRÓPICAS GLOBAIS DE METANO.

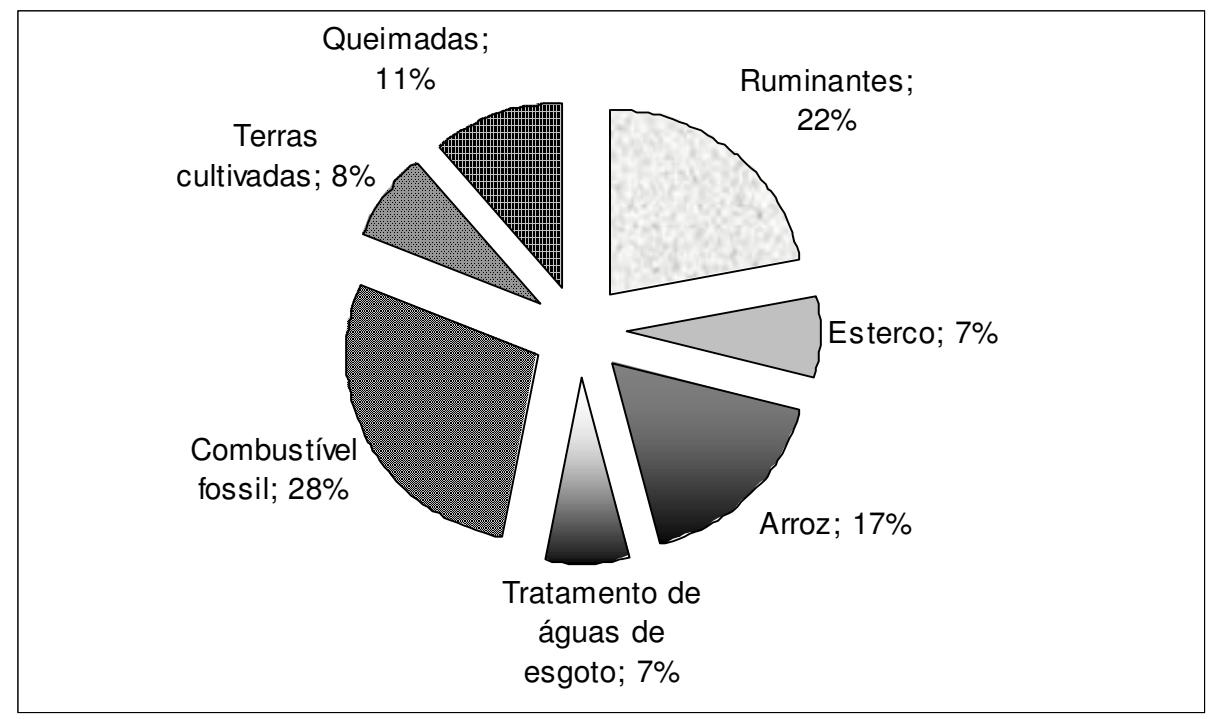

Adaptado de USEPA (2000). 
Estimativas da produção de metano de origem ruminal: No Brasil, em 1990, a emissão de $\mathrm{CH}_{4}$ proveniente da fermentação entérica de animais foi estimada em $7.940,99 \mathrm{Gg}\left(1 \mathrm{Gg}=10^{9} \mathrm{~g}\right)$, correspondendo a $96,3 \%$ do total de $\mathrm{CH}_{4}$ emitido pela pecuária (MCT, 2000), sendo o gado de corte responsável por $81,1 \%$ da emissão de $\mathrm{CH}_{4}$ por essa fonte.

Em 1995, foram estimadas emissões de 9,2 milhões $\operatorname{Tg}\left(1 \mathrm{Tg}=10^{12} \mathrm{~g}\right)$ de $\mathrm{CH}_{4}$ geradas pela pecuária, considerando os efetivos de ruminantes (bovinos, bubalinos, ovinos, caprinos) monogástricos (equinos, asininos, muares e suínos) e seus dejetos, sendo que $96 \%$ desse total foi atribuído à fermentação entérica, onde o gado de corte foi responsável por $81,6 \%$ (MCT, 2000).

A estimativa das emissões originadas dos processos de fermentação entérica, segundo MCT (2000), foi realizada subdividindo a pecuária em categorias de espécies consideradas emissoras, subdividindo a população de bovinos em gado de corte (constituído de fêmeas adultas, machos adultos e jovens) e vacas ordenhadas com posterior quantificação censitária (TABELA 2).

TABELA 2 - FATORES DE EMISSÃO DE METANO ORIGINADO DA FERMENTAÇÃO ENTÉRICA.

\begin{tabular}{llc}
\hline Categoria de animal & Sub-população & $\begin{array}{c}\text { Fator de emissão } \\
\mathrm{Kg} / \mathrm{cab} / \mathrm{ano}\end{array}$ \\
\hline Gado de corte & Fêmeas adultas & 58,00 \\
Gado de leite & Machos adultos & 57,00 \\
Ovinos & Jovens & 42,00 \\
Caprinos & Média & 57,00 \\
Suínos & Média & 5,00 \\
Média & 5,00 \\
\hline
\end{tabular}

Adaptado de MCT (2000).

Resultados iniciais de pesquisas desenvolvidas por PRIMAVESI et al. (2004) indicaram uma variação da emissão de $\mathrm{CH}_{4}$ por vacas em lactação de 14 a $16 \mathrm{~g}$ por hora ou $131 \mathrm{~kg} / \mathrm{cab} / \mathrm{ano}$, bastante superior aos valores apresentados por MCT (2000) (57 kg/cab/ano). Estas diferenças podem estar relacionadas com o tipo de animal utilizado para estimar a emissão do gás ou à utilização dos dados originados de animais criados em ambiente temperado, com diferentes sistemas de arraçoamento, principalmente com altos teores de grãos em sua dieta. JOHNSON et al. (1994) relataram que diversos trabalhos desenvolvidos com o inventário dos gases de efeito estufa assumiram um fator de emissão de $\mathrm{CH}_{4}$ de $55 \mathrm{~kg} / \mathrm{ano}$ para bovinos mantidos em paises desenvolvidos e $35 \mathrm{~kg} / \mathrm{ano}$ para animais criados em paises em desenvolvimento, mas, destacam que este é um fator médio de emissão extrapolado para um grupo variado de animais.

\section{Produção de metano decorrente da fermentação ruminal}

As Archaea metanogênicas, responsáveis pela produção de $\mathrm{CH}_{4}$, formam um grupo distinto de microrganismos, possuindo co-fatores (coenzima M, $\mathrm{F}_{420}, \mathrm{~F}_{430}$ ) e lipídeos (éteres de isopranil glicerol) únicos (McALLISTER et al., 1996). A parede celular destes microrganismos é composta por pseudomureina, proteína, glicoproteína ou heteropolisacarideos e a seqüência de nucleotídeos indica uma evolução inicial distinta das bactérias (ISHINO et al., 1998).

Embora várias espécies de metanogênicas tenham sido isoladas em diversos habitat anaeróbios, apenas cinco dessas espécies foram encontradas no rúmen, e destas apenas duas, Methanobrevibacter ruminantiume Methanosarcina sp., têm sido encontradas neste compartimento em populações maiores que $1 \times 10^{6} \mathrm{~mL}^{-1}$ (McALLISTER et al., 1996). No rúmen, as Archaea são encontradas intimamente associadas com protozoários ciliados e em justaposição com bactérias, não sendo essa, no entanto, uma localização obrigatória (FINLAY et al., 1994). Para USHIDA e JOUANY (1996), as metanogênicas podem ser encontradas tanto aderidas na superfície celular dos protozoários, como na fase intracelular dos mesmos. Considerando que os protozoários ciliados têm um grande potencial de produção de hidrogênio no rúmen (USHIDA e JOUANY, 1996), a associação somática das metanogênicas com estes ciliados indica uma relação simbiótica, em que as metanogênicas, por utilizarem o hidrogênio produzido pelos ciliados, favorecem a manutenção de um ambiente ruminal adequado ao desenvolvimento destes microrganismos (VAN SOEST, 1994).

A fermentação, que ocorre durante o metabolismo dos carboidratos ingeridos pelos ruminantes, é um processo anaeróbio, efetuado pela população microbiana ruminal, que converte os carboidratos em ácidos graxos de cadeia curta, principalmente ácidos acético (C2), propiônico (C3) e butírico (C4). Nesse processo fermentativo, são produzidos dióxido de carbono $\left(\mathrm{CO}_{2}\right)$ e $\mathrm{CH}_{4}$, em quantidades variáveis, dependendo da concentração e das proporções relativas dos ácidos produzidos (OWENS e GOETSCH, 1988; EUN et al., 2004) ).

A proporção dos ácidos graxos voláteis (AGV) no rúmen depende da dieta, sendo que rações ricas em 
Aspectos relacionados com a emissão de metano de origem ruminal em sistemas de produção de bovinos

grãos favorecem a maior formação do ácido propiônico, enquanto que rações com alta proporção de alimentos volumosos favorecem a produção de ácido acético (OWENS e GOETSCH, 1988).

As equações apresentadas na FIGURA2 caracterizam a perda de hidrogênio e carbono para cada tipo de ácido graxo formado. Supondo uma proporção AGV de uma amostra de líquido ruminal de 62, 22 e 16\% para o ácido acético, propiônico e butírico, respectivamente, a maior produção de $\mathrm{H}_{2}$ ocorre durante a produção do ácido acético (HUNGATE, 1966), acarretando em maior produção de $\mathrm{CH}_{4}$, já que o $\mathrm{H}_{2}$, para ser eliminado, liga-se a moléculas de $\mathrm{CO}_{2}$, em um processo realizado pelas metanogênicas (KRUMHOLZ et al., 1983). Este fato leva a um sistema de equilíbrio, pois à medida que ocorre a fermentação dos carboidratos no rúmen, aumentam os teores de hidrogênio que, se não forem removidos, inibem os sistemas enzimáticos, principalmente os processos que envolvem a nicotinamida adenosina difosfato (MILLER, 1995).

FIGURA 2 - ESQUEMA DE PRODUÇÃO DE AGV NO RÚMEN.

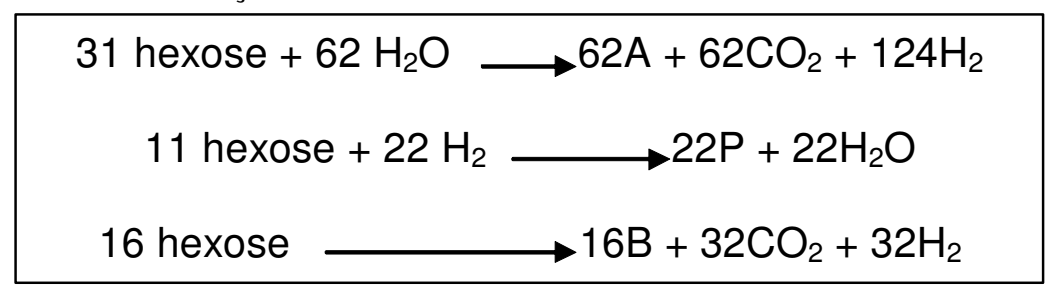

Adaptado de HUNGATE (1966).

McSWEENEY e McCRABB (2001) relataram que os efeitos adversos do acúmulo de $\mathrm{H}_{2}$ no rúmen incluem a inibição da re-oxidação do NADH e o acúmulo de lactato ou etanol, o que proporciona queda de $\mathrm{pH}$, tendo como conseqüência a redução da eficiência do crescimento de microrganismos que degradam a fibra da dieta. A pressão-parcial de $\mathrm{H}_{2}$ influencia no metabolismo de duas importantes espécies
(Ruminococcus albus e Ruminococcus flavefaciens) que degradam a fibra no rúmen (WOLIN e MILLER, 1988). Este fato ocorre devido aos efeitos depressivos que $\mathrm{O}$ acúmulo de $\mathrm{H}_{2}$ exerce sobre a transferência interespécies de hidrogênio. Assim, as espécies celulolíticas, tais como $R$. albus, em monocultura, produzem etanol, acetato, $\mathrm{H}_{2}$, e $\mathrm{CO}_{2}$ quando $\mathrm{H}_{2}$ é acumulado (FIGURA 3).

FIGURA 3 - FERMENTAÇÃO DE CARBOIDRATOS POR Ruminococos albus.

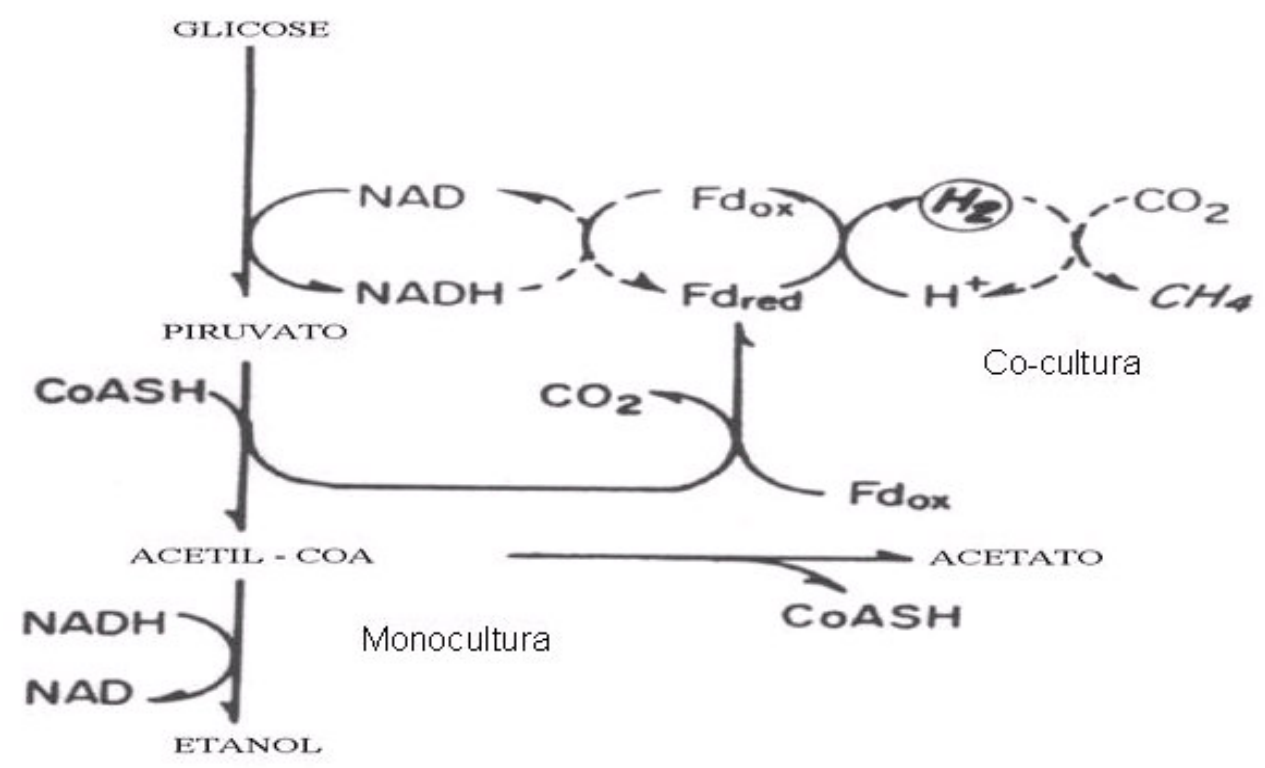

Adaptado de WOLIN e MILLER, 1988. 
Nesta situação, o NADH é re-oxidado e utilizado para produzir etanol à partir do acetil-coA. Quando em cocultura com metanogênicas, a formação de etanol cessa ou é drasticamente reduzida, levando a uma maior produção de ATP por unidade de hexose fermentada (WOLIN e MILLER, 1988).

$\mathrm{O}$ ciclo de produção de $\mathrm{CH}_{4}$ apresentado (FIGURA 4) mostra as enzimas e as etapas para a formação do $\mathrm{CH}_{4}$ a partir do $\mathrm{CO}_{2}$ (ROUVIERE e
WOLFE, 1988). MILLER (1995) relatou que, embora o acetato seja um importante substrato para a produção de $\mathrm{CH}_{4}$, são poucas as metanogênicas que utilizam o grupo metil do acetato para este fim, sendo $\mathrm{O}_{2}$ e o $\mathrm{CO}_{2}$ os substratos mais importantes, sendo ainda que a maioria das metanogênicas utiliza a metanol oxidase para produzir os elétrons necessários para reduzir três moléculas de metanol a $\mathrm{CH}_{4}$.

\section{FIGURA 4 - ROTA METABÓLICA DA PRODUÇÃO DE METANO A PARTIR DO $\mathrm{CO}_{2}$}

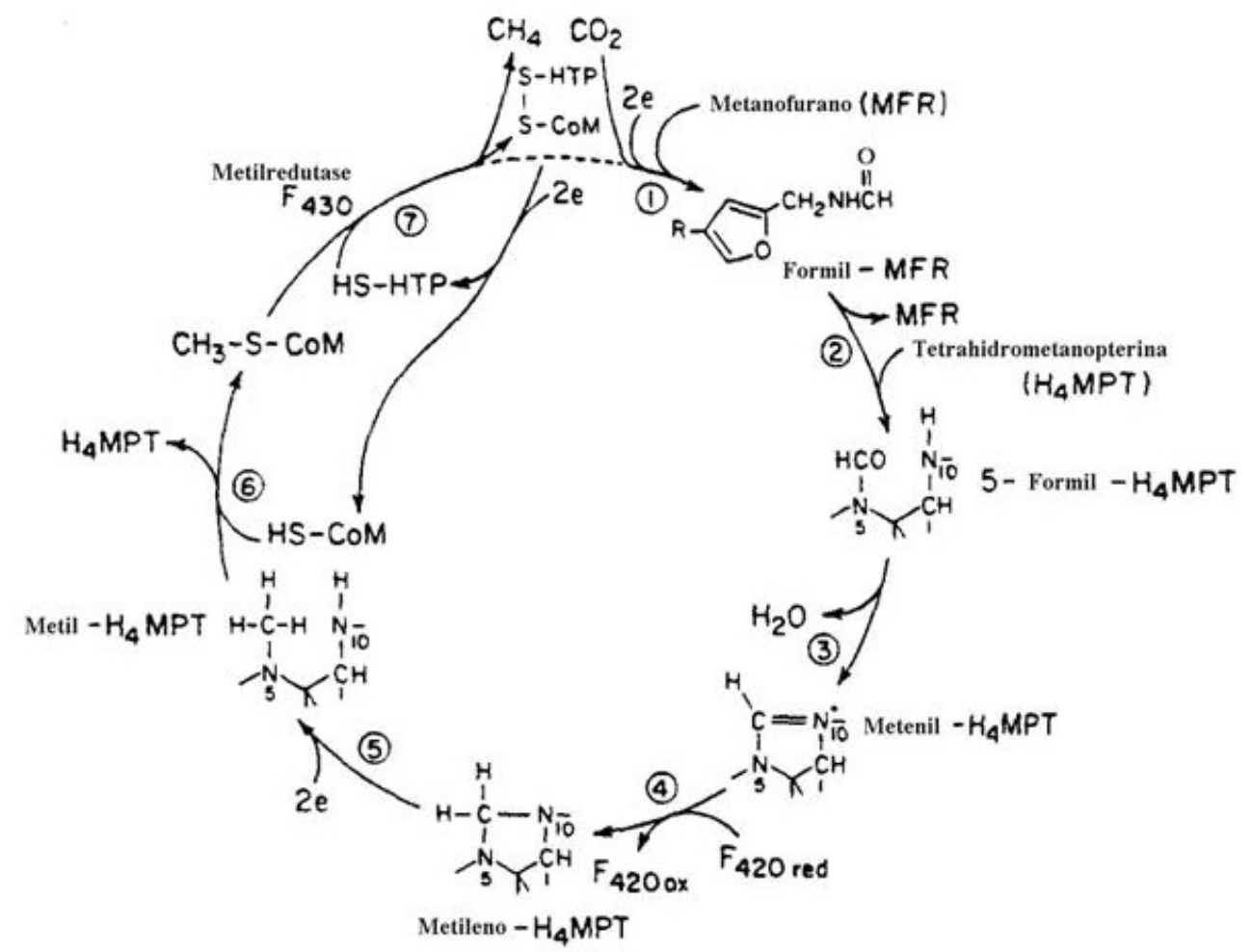

Adaptado de ROUVIERE e WOLFE (1988).

\section{Variação da produção de metano no rúmen}

Os estudos realizados por MILLER (1995), JOHNSON e JOHNSON (1995) e McALLISTER et al. (1996) revelaram que a emissão de $\mathrm{CH}_{4}$ proveniente da fermentação ruminal depende principalmente do tipo de animal, nível de consumo de alimentos, tipo de carboidratos presentes na dieta, processamento da forragem, adição de lipídeos no rúmen, suprimento de minerais, manipulação da microflora ruminal e da digestibilidade dos alimentos. Por essas razões, as indicações para a redução das emissões de $\mathrm{CH}_{4}$ pela pecuária estão ligadas a medidas que refletem na melhor eficiência produtiva.

Dietas que possuem grande participação de volumosos podem representar perdas energéticas para os animais, em relação à energia inicial consumida, que variam de 6 a 18\% (OWENS e GOETSCH, 1988). De acordo com JOHNSON e JOHNSON (1995), em dietas compostas por cerca de $90 \%$ de alimentos concentrados, as perdas de energia na forma de $\mathrm{CH}_{4}$ podem ser variáveis, encontrando-se perdas em torno de 2 a $3 \%$, o que representa aproximadamente a metade do valor normalmente relatado $(6 \%)$.

O incremente na utilização de energia é citado na literatura como estratégia mais eficaz na redução na emissão de $\mathrm{CH}_{4}$ por unidade de produto (carne ou leite) pelos ruminantes (O'HARA et al., 2003; LOVETT et al., 2005). O fornecimento de dietas que possuem em maior quantidade carboidratos rapidamente digestíveis, a manutenção de altos níveis de ingestão, a utilização de forragens de melhor qualidade e o melhoramento genético dos animais, priorizando maior desempenho produtivo, constituem os principais recursos conhecidos e disponíveis (O'HARA et al., 2003). MOSS e GIVENS (2002) citam que o desempenho mais elevado dos 
Aspectos relacionados com a emissão de metano de origem ruminal em sistemas de produção de bovinos

animais pode reduzir a emissão de $\mathrm{CH}_{4}$ em função da redução no número de animais no sistema de produção, considerando ainda que, em criações que visam produção de carne, o acréscimo no desempenho dos animais resulta em menor permanência do animal no sistema, reduzindo a produção do gás durante o ciclo de vida.

A qualidade de alimento fornecido (AAFC, 2003; JOHNSON e JOHNSON, 1995), como citado anteriormente, constitui-se em importante fator que afeta a taxa de emissão de $\mathrm{CH}_{4}$. Em geral, dietas que proporcionam alta taxa de digestão reduzem a emissão de $\mathrm{CH}_{4}$, já que o alimento não permanece por tempo prolongado no rúmen (AAFC, 2003). A quantidade de forragem na dieta, método de preservação, estágio de crescimento da planta forrageira, tamanho de partícula e grau de moagem, a quantidade de grãos na dieta, a adição de lipídeos e aditivos, como os ionóforos, são importantes componentes que afetam e estão envolvidos na produção de $\mathrm{CH}_{4}$ no rúmen (JOHNSON e JOHNSON, 1995).

OLSON et al. (2000) trabalhando com a quantificação da emissão de $\mathrm{CH}_{4}$ por bovinos de corte em diferentes sistemas de pastagens nativas não observaram diferenças nas taxas de emissão desse gás quando melhoraram a qualidade dos pastos por meio da introdução de espécies forrageiras de melhor valor nutritivo. Entretanto, McCAUGHEY et al. (1999) apresentaram resultados que indicaram uma influência positiva do melhoramento da qualidade do pasto, por meio da introdução de leguminosas, na redução da produção de $\mathrm{CH}_{4}$. A melhoria na qualidade dos pastos, com consequente aumento na produtividade animal, é também citado por DERAMUS et al. (2003) como redutor da produção de $\mathrm{CH}_{4}$ resultante da fermentação ruminal.

Em regiões tropicais estes aspectos podem se comportar de maneira diferente, uma vez que a composição química e a digestibilidade das forrageiras utilizadas na alimentação dos bovinos são distintas daquelas utilizadas em regiões temperadas. A relação parede celular:conteúdo celular e a constituição da parede celular das plantas forrageiras tropicais, mais especificamente das gramíneas, são os principais fatores envolvidos. Estas plantas apresentam maiores conteúdos de parede celular e menores taxas de digestibilidade (VAN SOEST, 1994).

As características das gramíneas $\mathrm{C}_{4}$ podem conduzir a diferentes interpretações quanto ao potencial de fornecimento de substrato para fermentações que geram $\mathrm{CH}_{4}$ no rúmen. Estas plantas forrageiras, por possuírem maiores proporções de fibra que as plantas de metabolismo $\mathrm{C}_{3}$ (NELSON e MOSER, 1994) devem favorecer a fermentação acética, com maior produção de $\mathrm{CH}_{4}$. Por outro lado, esta fibra apresenta baixa digestibilidade e menor velocidade de fermentação, quando comparadas às plantas de clima temperado, fornecendo menor quantidade de substrato para os microrganismos metanogênicos.
O aumento do valor alimentício das dietas tem sido considerado uma das principais indicações feitas para a redução do $\mathrm{CH}_{4}$ por bovinos. Entretanto, esse fato deve ser analisado considerando todos os aspectos que envolvem a atividade e não de forma isolada, principalmente quando se incluem alimentos concentrados à dieta dos animais. Nesta situação, os gastos energéticos envolvidos na produção de grãos devem ser considerados, pois, muitas vezes, a redução da emissão de $\mathrm{CH}_{4}$ de origem ruminal, causada pela inclusão desses alimentos à dieta, é compensada por um incremento muito maior da emissão de $\mathrm{CO}_{2}$ proveniente da queima de energia fóssil pelas máquinas envolvidas nos processos de produção e transporte de grãos. Bem como, pode haver grande geração de óxido nitroso (gás de efeito estufa 25 vezes mais potente em reter calor que $\circ \mathrm{CH}_{4}$ ), oriundo do nitrato gerado pelos fertilizantes nitrogenados aplicados nas lavouras de grãos e pastagens, quando submetidos a condições anaeróbicas, durante períodos de chuvas ou de irrigação.

\section{Inibidores da Produção de Metano}

A partir das informações apresentadas, observa-se que a utilização de recursos que atuem na redução da emissão de $\mathrm{CH}_{4}$ de origem ruminal resultam em benefícios econômicos, pela maior eficiência na utilização dos alimentos e, principalmente, benefícios para o meio ambiente (McGINN et al., 2004).

A redução de $\mathrm{CO}_{2}$ a $\mathrm{CH}_{4}$, realizada pelas metanogênicas no rúmen, desempenha importante função, agindo na remoção contínua de $\mathrm{H}_{2}$ resultante da fermentação da matéria orgânica. Dessa forma a redução ou eliminação da metanogênese pode exigir o estabelecimento de outra rota para evitar o acúmulo de $\mathrm{H}_{2}$ e o adequado funcionamento do rúmen (WEIMER, 1998), caso contrário, determinados sistemas enzimáticos podem ser inibidos comprometendo o desenvolvimento dos microrganismos ruminais. Normalmente, compostos que causam redução na produção de $\mathrm{CH}_{4}$ resultam em redução da produção de acetato e amônia e aumento na produção de propionato e, algumas vezes, butirato (GARCIA-LOPEZ et al., 1996).

O fornecimento de lipídeos insaturados está associado à redução na produção de $\mathrm{CH}_{4}$ no rúmen por exercer ação deletéria sobre as metanogênicas e protozoários e consumir $\mathrm{H}_{2}$ pelo processo de biohidrogenação (MACHMÜLLER et al., 1998), sendo que a intensidade com que ocorre a inibição da produção de $\mathrm{CH}_{4}$ é determinada pelo grau de saturação da gordura utilizada e a quantidade suplementada (FIEVEZ et al., 2003). Em trabalho avaliando o efeito do fornecimento de ácido graxos de cadeia média, MACHMÜLLER (2006) encontrou que mesmo em concentrações inferiores a $3 \%$ da dieta, a suplementação com os ácidos graxos C12:0 e C14:0 é responsável pela redução de $50 \%$ na produção de $\mathrm{CH}_{4}$ 
em ruminantes. No entanto, WEIMER (1998) cita que a utilização de alimentos comumente fornecidos na alimentação animal pode apresentar baixa eficiência como aceptor de elétrons, reduzindo de forma insignificante a metanogênese. Por exemplo, a quantidade de gordura insaturada para reverter a perda causada pela produção do gás em uma vaca que produz $90 \mathrm{~kg}$ de $\mathrm{CH}_{4}$ por ano seria muito alta $(4 \mathrm{~kg} / \mathrm{d})$, inviabilizando assim o emprego da técnica.

Os ionóforos, principalmente a monensina, são aditivos empregados na alimentação de ruminantes, e trabalhos têm mostrado seu efeito inibitório na produção de $\mathrm{CH}_{4}$ de origem ruminal (DOMESCIK e MARTIN, 1999; LANA e RUSSELL, 2001). De acordo com TEDESCHI et al. (2003), os ionóforos podem reduzir a produção de $\mathrm{CH}_{4}$ em $25 \%$ e a ingestão de alimentos em 4\%, sem afetar o desempenho animal. A molécula de monensina é um poliéter carboxílico, devendo ser não-protonado, que se liga a íons metálicos catalisando a saída de potássio através da membrana das bactérias sensíveis, as Gram-positivas (maiores produtoras de $\mathrm{H}_{2}$ ) (LANNA e RUSSELL, 2001). No entanto, SAUER et al. (1998) citam que mesmo as bactéria Gram-positivas podem desenvolver mecanismos de resistência após um período e exposição à monensina, entre eles, modificação nos polissacarídeos extracelulares, aumento na atividade da bomba de íons e ciclo fútil de íons. JOHNSON e JOHNSON citam que a adaptação pode ocorrer com 30 dias de administração da monensina, observando que após a queda na produção de $\mathrm{CH}_{4}$, no início do fornecimento do produto, os valores retornam aos níveis iniciais, acrescentando também que a ação da monesnina na redução da produção de $\mathrm{CH}_{4}$ se dá, possivelmente, por meio da redução no consumo e não por efeito direto sobre a metanogenênese.

Outra substância empregada com resultados satisfatórios sobre a inibição da emissão de $\mathrm{CH}_{4}$ é 9,10antraquinona, composto de ocorrência natural em algumas plantas, insetos e microrganismos (GARCIALOPEZ et al., 1996). KUNG Jr. et al. (2003) citam que a 9,10-antraquinona é um potencial redutor da produção do gás em ruminantes, apresentando como vantagens resultados mesmo quando presente em pequenas quantidades, não causar efeito negativo sobre a digestão ou saúde animal e aparentemente não ocorrer adaptação à substância. GARCIA-LOPEZ et al. (1996) demonstraram que a redução na produção de $\mathrm{CH}_{4}$ foi acompanhada do aumento na concentração ruminal de $\mathrm{H}_{2}$. $\mathrm{O}$ acúmulo de $\mathrm{H}_{2}$ sugere que provavelmente a 9,10antraquinona possui efeito direto sobre as metanogênicas, enquanto que ionóforos, como a monensina, inibem a produção de $\mathrm{CH}_{4}$ por afetar negativamente os microrganismos que suprem com $\mathrm{H}_{2}$ o ambiente ruminal.

A utilização de forragens com presença de tanino condensado, um composto de defesa produzido pelo metabolismo secundários das plantas, também vem sendo reportado pela literatura (WOODWARD et al., 2001; PUCHALA et al., 2005), com resultados bastante promissores, indicando possível efeito deletério do tanino condensado sobre as bactérias metanogênicas. A utilização de drenos alternativos para remoção de $\mathrm{H}_{2}$ constitui-se em outra alternativa para redução da metanogênese. Segundo WEIMER (1998) a melhor alternativa é o processo de acetogênese, onde o $\mathrm{CO}_{2}$ é reduzido produzindo acetato. Esse processo apresenta como vantagens a utilização de $\mathrm{H}_{2}$ presente no meio e a produção de acetato, que representa fonte de energia prontamente disponível para o ruminante. Entretanto, esse processo encontra determinadas barreiras. Entre elas, a principal é que a metanogênese possui maior afinidade por elétrons do que a acetogênese. A capacidade dos microrganismos acetogênicos em competir com os metanogênicos in vivo depende dos fatores ambientais e das interações entre os microrganismos. As interações entre diferentes populações são essenciais para sustentar o ecossistema. A maior vantagem da utilização desta estratégia é que consiste em um processo natural, onde intervenções envolvendo antibióticos e aditivos químicos deixam resíduos no leite e carne podendo causar uma resistência aos produtos pelos consumidores (JOBLIN, 1999).

LOPEZ et al. (1999) citam que, em determinadas situações, as acetogênicas não são capazes de competir com as metanogênicas, pela sua menor afinidade por $\mathrm{H}_{2}$, e conclui que sob condições normais de rúmen, apesar de sua habilidade de formar acetato a partir de $\mathrm{CO}_{2}$ e $\mathrm{H}_{2}$ mesmo em grande concentração, as bactérias acetogênicas não podem competir com as metanogências.

\section{Considerações Finais}

Uma vez que a produção de $\mathrm{CH}_{4}$ varia de acordo com a quantidade e qualidade do alimento ingerido, as várias modalidades e condições de sistemas de criação dos ruminantes implicam em fatores diferentes de emissão de $\mathrm{CH}_{4}$. O fornecimento de alimentos de melhor qualidade tem sido considerado uma das principais indicações para a redução do $\mathrm{CH}_{4}$ por bovinos. A possibilidade de maximizar a utilização de energia dos alimentos e o consequente aumento da produtividade animal possibilita a redução na produção do gás por unidade de produto gerado, além de diminuir o tempo necessário para que o animal finalize seu ciclo produtivo, no caso de gado de corte. Entretanto, os vários aspectos envolvidos na cadeia de produção animal, no que se refere desde a produção de alimentos até a obtenção do produto final devem ser considerados, elegendo sistemas que possibilitem a redução da emissão de gases poluidores para a atmosfera.

\section{Referência Bibliográficas}

AGRICULTURAL AND AGRI-FOOD CANADA - AAFC. Estimates of emissions: methane. Disponivel em: $<$ http://www.agr.ca/research/Healthy_Air> On line. Acesso em: 10 jul. 2003. 
Aspectos relacionados com a emissão de metano de origem ruminal em sistemas de produção de bovinos

COTTON, W.R.; PIELKE, R.A. Human impacts on weather and climate. Cambridge: Cambridge University, 1995. 288p.

DERAMUS, H.A.; CLEMENT, T.C.; GIAMPOLA, D. D.; DICKISON, P.C. Methane Emissions of beef cattle on forages: efficiency of grazing management systems. Journal of Environmental Quality, Madison, v.32, p.269-277, 2003.

DOMESCIK, E.J.; MARTIN, S.A. Effects of laidlomycin propionate and monensin on the in vitro mixed ruminal microorganism fermentation. Journal of Animal Science, Savoy, v.77, p.2305-2312, 1999.

EUN, J.S.; FELLNER, V.; GUMPERTZ, M.L. Methane production by mixed ruminal cultures incubated in dualflow fermentors. Journal of Dairy Science, Savoy, v.87, p.112-121, 2004.

FIEVEZ, V., DOHME, F., DANNEELS, M., RAES, K., DEMEYER, D. Fish oils as potent rumen methane inhibitors and associated effects on rumen fermentation in vitro and in vivo. Animal Feed Science and Technology, Amsterdam, v.104, p.41-58, 2003.

FINLAY, B.J.; ESTEBAN, G.; CLARKE, K.J.; WILLIAMS, A.G.; EMBLEY, T.M; HIRT, R.P. Some rumen ciliates have endosymbiotic methanogens. FEMS Microbiology Letters, Delft, v.117, p.157-161, 1994.

GARCIA-LOPEZ, P.M.; KUNG Jr., L.; ODOM, J.M. In vitro inhibition of microbial methane production by 9,10 anthraquinone. Journal of Animal Science, Savoy, v.74, p.2276-2284, 1996.

HARPER, L.A.; DENMEAD, O.T.; FRENEY, J.R.; BYERS, F.M. Direct measurements of methane emissions from grazing and feedlot cattle. Journal of Animal Science, Savoy, v.77, p.1392-1401, 1999.

HUNGATE, R.E. The rumen and its microbes. New York: Academic, 1966. 533p.

ISHINO, Y., KOMORI, K., CANN, I.K.O. ; KOGA, Y. A novel DNA polymerase family found in Archaea. Journal of Bacteriology, Washington, v.180, p.2232-2236, 1998.

JOBLIN, K.N. Ruminal acetogens and their potential to lower ruminant methane emissions. Australian Journal of Agricultural Research, Collingwood, v.50, p.13071313, 1999.

JOHNSON, K.A.; JOHNSON, D.E. Methane emissions from cattle. Journal of Animal Science, Savoy, v.73, p.2483-2492, 1995.

JOHNSON, K.A., HUYEL, M., WESTBERG, H. LAMB, B.; ZIMMERMAN, P. Measurement of methane emissions from ruminant livestock using a $\mathrm{SF}_{6}$ tracer technique. Environmental Science and Technology, Washington, v.28, p.359-362, 1994.

KRUMHOLZ, L.R.; FORSBERG, C.W.; VEIRA, D.M. Association of methanogenic bacteria with rumen protozoa. Canadian Journal of Microbiology, Ottawa, v.29, p.676-680, 1983.
KUNG Jr., L., SMITH, K.A., SMAGALA, A.M., ENDRES, K.M., BESSETT, C.A., RANJIT, N.K., YAISSLE, J. Effects of 9,10 anthraquinone on ruminal fermentation, total-tract digestion, and blood metabolite concentrations in sheep. Journal of Animal Science, Savoy, v.81, p.323-328, 2003.

LANA, R.P.; RUSSELL, J.B. Efeitos da monensina sobre a fermentação e sensibilidade de bactérias ruminais de bovinos sob dietas ricas em volumoso ou concentrado. Revista Brasileira de Zootecnia, Viçosa, v.30, p.254-260, 2001.

LOPEZ, S.; McINTOSH, F.M.; WALLACE, R.J.; NEWBOLD, C.J. Effect of adding acetogenic bacteria on methane production by mixed rumen microorganisms. Animal Feed Science and Technology, Amsterdam, v.78, p.1-9, 1999.

LOVETT, D.K.; STACK, L. J. ; LOVELL, S.; CALLAN, J.; FLYNN, B; HAWKINS, M.; O'MARA, F.P. Manipulating enteric methane emissions and animal performance of late-lactation dairy cows through concentrate supplementation at pasture. Journal of Dairy Science, Savoy, v.88, p.2836-2842, 2005.

MACHMÜLLER, A. Medium-chain fatty acids and theeir potential to reduce methanogenesis in domestic ruminants. Agriculture, Ecosystems and Environment, Amsterdam, v.112, p.107-114, 2006.

MACHMÜLLER, A., OSSOWSKI, D.A., WANNER, M., KREUZER, M. Potential of various fatty feeds to reduce methane release from rumen fermentation in vitro (Rusitec). Animal Feed Science and Technology, Amsterdam, v.71, p.117-130, 1998.

McGINN, S.M.; BEAUCHEMIN, K.A.; COATES, T.; COLOMBATTO, D. Methane emissions from beef cattle: Effects of monensin, sunflower oil, enzymes, yeast, and fumaric acid. Journal of Animal Science, Savoy, v.82, p.3346-3356, 2004.

McSWEENEY, C.S.; McCRABB, G.J. Inhibition of rumen methanogenesis and its effects on feed intake, digestion, and animal production. In: INTERNACIONAL CONFERENCE ON GREENHOUSE GASES AND ANIMAL AGRICULTURE - GGAA, 1., 2001, Hokkaido. Proceedings... Hokkaido: Greenhouse Gases and Animal Agriculture, 2001. p.96-104.

McALLISTER, A.T., OKINE, E.K., MATHISON, G.W.; CHENG, K.J. Dietary, environmental and microbiological aspects of methane production in ruminants. Canadian Journal of Animal Science, Ottawa, v.76, p. 231-243, 1996.

McCAUGHEY, W. P.; WITTENBERG, K.; CORRIGAN, D. Inpact of pasture type on methane production by lactating beef cows. Canadian Journal of Animal Science, Ottawa, v.79, p.221-226, 1999.

MILLER, T.L. Ecology of methane production and hydrogen sink in the rumen. In: ENGELHARDT, W. V., LEONHARD-MAREK, S., BREVES, G., GIESSECKE, D. (Ed). Ruminant Physiology: Digestion, metabolism, growth and reproduction. Stuttgart: Ferdinand Enke Verlag. 1995. p. 317-332. 
MINISTÉRIO DA CIÊNCIA E TECNOLOGIA - MCT. Convenção sobre Mudança do Clima. Disponívelem:<http://www.mct.gov.br/clima/comunic_old/ pecuar01.htm>. On line. Acesso em: 11 dez. 2000.

MOSS, A.R.; GIVENS, D.I. The effect of supplementing grass silage with soya bean meal on digestibility, in sacco degradability, rumen fermentation an methane production in sheep. Animal Feed Science and Technology, Amsterdam, v.97, p.127-143, 2002.

NELSON, C.J.; MOSER, L.E. Plant factors affecting forage quality. In: FAHEY Jr., G.C. (Ed). Forage quality, evaluation and utilization. Madison: American Society of. Agronomy., 1994. p.115-154.

O'HARA, P.; FRENEY, J.; ULYATT, M. Abatement of agricultural non-carbon dioxide greenhouse gas emissions: a study of research requirements. Report prepared for the Ministry of Agriculture and Forestry on Behalf of the Convenor, Ministerial Group on Climate Change, the Minister of Agriculture and the Primary Industries Council. New Zealand: Crown Copyright - Ministry of Agriculture and Forestry, 2003. 170p. Disponível em: <www.maf.govt.nz/publications>. On line. Acesso em: 01 mar. 2004.

OLESEN, J.E.; SCHELDE, K.; WEISKE, A.; WEISBJERG, M.R.; ASMAN, W.A.H.; DJURHUUS, J. Modelling greenhouse gas emissions from European conventional and organic dairy farms. Agriculture, Ecosystems and Environment, Amsterdam, v.112, p.207-220, 2006.

OLSON, K. C., BANNER, R. E., WIEDMEIER, R. D. et al. Reducing methane emission from beef cow herds in rangebased management systems In: Final report to the ruminant livestock efficiency program atmospheric pollution prevention division United States Environmental Protection Agency. Logan: Utah State University, 2000. 31p.

OWENS, F.N.; GOETSCH, A.L. Ruminal fermentation. In: $\mathrm{CHURCH}$, D.C. (Ed) The ruminant animal: digestive physiology and nutrition. Waveland Press, 1988. p.145-171.

PRIMAVESI, O., FRIGHETTO, R.T.S., LIMA, M.A.; BERCHIELLI, T.T.; BARBOSA, P.F. Metano entérico de bovinos leiteiros em condições tropicais brasileiras. Pesquisa Agropecuária Brasileira, Brasília, v.39, p.277-283, 2004.
PUCHALA, R.; MIN, B.R.; GOETSCH, A.L.; SAHLU, T. The effect of a condensed tannin-containing forage on methane emission by goats. Journal of Animal Science, Savoy, v.83, p.182-186, 2005.

ROUVIERE, P.E.; WOLFE, R.S. Novel biochemistry of methanogenesis. Journal of Biological Chemistry, Stanford, v.263, p.7913-7916, 1988.

SAUER, F.D., FELLNER, V., KINSMAN, R., KRAMER, J.K.G., JACKSON, H.A., LEE, A.J., CHEN, S. Methane output and lactation response in holstein cattle with monensin or unsaturated fat added to the diet. Journal of Animal Science, Savoy, v.76, p.906-914, 1998.

TEDESCHI, L.O.; FOX, D.G.; TYLUTKI, T.P. Potential Environmental Benefits of lonophores in Ruminant Diets. Journal of Environmental Quality, Madison, v.32, p.1591-1602, 2003.

UNITED STATES ENVIROMENTAL PROTECTION AGENCY - USEPA. Evaluating Ruminant Livestock Efficiency Projects and Programs In: PEER REVIEW DRAFT. Washington, D.C, 2000, 48p.

USHIDA, K.; JOUANY, J.P. Methane production associated with rumen-ciliated protozoa and its effect on protozoan activity. Letters Applied Microbiology, Oxford, v.23, p.129-132, 1996.

VAN SOEST, P.J. Nutritional ecology of the ruminant. 2. ed. Ithaca: Cornell University, 1994. 476p.

WEIMER, P.J. Manipulating ruminal fermentation: a microbial ecological perspective. Journal of Animal Science, Savoy, v.76, p.3114-3122, 1998.

WOODWARD, S.L.; WAGHORN, G.C.; ULYATT, M.J.; LASSEY, K.R. Early indications that feeding Lotus will reduce methane emissions from ruminants. In: THE NEW ZEALAND SOCIETY OF ANIMAL PRODUCTION, 2001, Adelaide. Proceedings... Adelaide: ACIAR, 2001. p.23-26.

WOLIN, M.J.; MILLER, T.L. Microbe-microbe interactions. In: HOBSON, P.N. (Ed.) The rumen microbial ecosystem. New York: Elsevier, 1988. p.343-359.

Recebido para publicação:

$18 / 11 / 2005$

Aprovado:

$22 / 02 / 2006$ 